\title{
Assessment of Vulnerability Index (CVI) of Central Coast of Albania
}

\author{
Besnik Ago ${ }^{1}$, Dr. Shkëlqim Daja ${ }^{1}$, Dr. Çerçis Durmishi ${ }^{2}$ \\ ${ }^{1}$ MSc., Department of Applied Geology and Geoinformatics, Faculty of Geology and Mining, Polytechnic University of Tirana, Albania \\ ${ }^{2}$ Associate Professor, Department of Applied Geology and Geoinformatics, Faculty of Geology and Mining, Polytechnic University of \\ Tirana, Albania \\ ${ }^{2}$ Professor, Department of Earth Sciences, Faculty of Geology and Mining, Polytechnic University of Tirana, Albania \\ besnik.ago@fgjm.edu.al
}

\begin{abstract}
The coastal vulnerability index (CVI) is used as an indicator for the estimation of relative vulnerability of different segments in the central part of the Albanian Coast. In this area, the sandy beach has suffered strong erosions in the last 20 years. In particular, in different segments situated at Karpen - Qerret lowland, during the last years the annual erosion rates reach values up to $40 \mathrm{~m} / y e a r$. In order to calculate the CVI, geological and physical parameters are used. The geological parameters consist in geomorphology, regional coastal slope and shoreline erosion/accretion rate, while the physical parameters are the relative sea-level rise rate,mean tide range and the mean wave height. The Geographical Information System (GIS) is used for mapping the coastal vulnerability of various segments of the study area.
\end{abstract}

Keywords: Coastal Vulnerability Index (CVI), Albania

\section{Introduction}

Albania is a typical coastal country. The entire costal line, with a length of $476 \mathrm{~km}$, borders two seas - the Adriatic and Ionian Sea - which are part of the Mediterranean Sea. [1].

In the last years, an advancement of the sea towards the land is observed, in some cases reaching in certain areas a rate of a dozen meters per year. This is evident especially in sandy low beaches of the central parts of the Albanian coast. In the absence of investments for the protection from erosion, individual interventions have been undertaken, giving the coastline an irregular and unpleasant arrangement. The creation of a National Agency for the Coast has not obtained any concrete results in the prevention of erosion because this agency appears to be more concerned with the sea than with the coast.

Partial studies of the coastal area from the Albanian Geological Survey are limited to identifying the segments with erosion and accretion, at occasions also giving the corresponding annual rates, which have been of little use to the interested sides, such as local units or the various central agencies that are responsible for urban planning. This article, for the first time in Albania, aims at conducting a vulnerability analysis of the coastline in relation to the relative sea level rise, by means of an Index-Based Method which uses CVI (Coastal Vulnerability Index) as an indicator of vulnerability. GIS mapping of this index will equip the urban planners with an important tool for planning the potential protection works as well as for drafting the development plans the coastal areas.

\section{Study Area}

The study area (Figure 1) is the central part of Albanian coast from the river mouth of Shkumbini River to that of
Erzeni River, for a length of about $57 \mathrm{~km}$ extending between easting $360000 \mathrm{~m}$ and $380000 \mathrm{~m}$ (UTM) and northing 4542500 Nand $4587000 \mathrm{~m}$ (UTM). Coastal zones along the study area suffer permanent erosionespecially in the lowlands. Near the river mouth of Shkumbini River, it can be observed an accumulative sector formed as a result of the migration of the river mouth in the northern direction to a distance of around $5 \mathrm{~km}$ in the mid 1980's. In the northern direction in the Durresi Bay, the erosion processes are observed, particularly in its southern part. The hilly parts, such as the Synej, Durresi and Bishti i Palles Hills, demonstrate a stability in the shoreline position.

\section{Methodology}

The methodology used in this study consists of the GIS mapping of the different classes of vulnerability using the CVI (coastal Vulnerability Index. This index is calculated for two time periods, respectively 1975-1990 and 19902017. The political changes after 1990 in Albania brought about an overall change in the way of territory utilization and exploitation of the natural resources. The demographic developments, population migrations towards coastal areas, the development of the construction industry, as well as other factors, have led to the disturbance of the natural equilibrium in these areas. The exploitation of riverbeds for extracting construction materials has caused the reduction of solid discharge of rivers leading to a lack of sediments for the near-shore transportation, consequently causing the increase of erosion in coastal areas.

As a first step, the key factors that influence the coastal vulnerability and the dynamic of the coastline in general, were identified. The variables used were the ones proposed byGornitz et al, 1990 [9], divided into two groups: 
- geological parameters include the relief, the rock type, geomorphology and the coastline changes (erosion/accretion)

- physical parameters include sea surface changes expressed in vertical movement, the significant wave height, and theaverage tide height.
The second step deals with the quantitative evaluation of the factors, according to Gornitz et al, 1990 as in the following table:

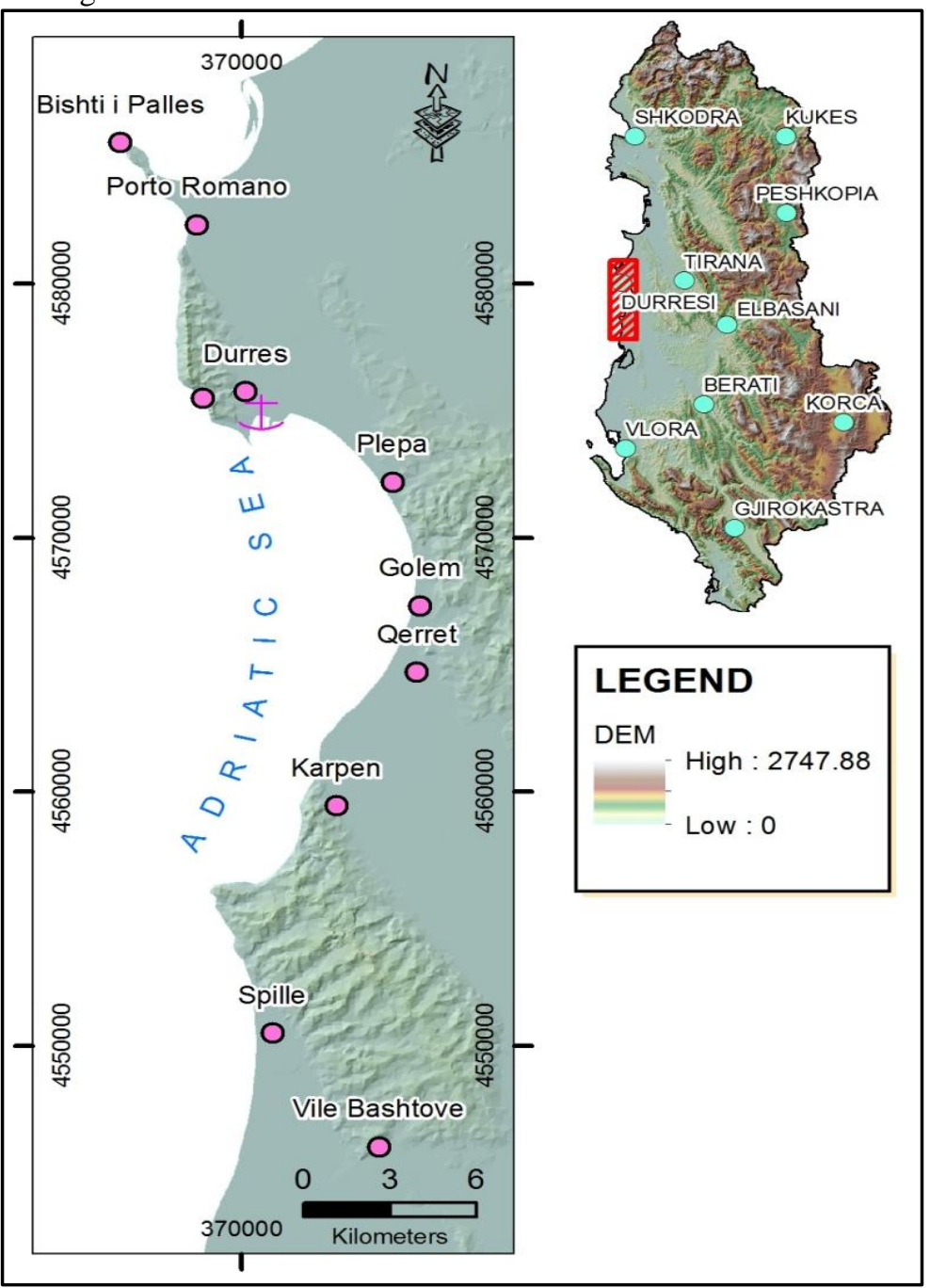

Figure 1: Geographical location of the study area

Table 1: Parameter ranking after Gornitz et al, 1990 [9]

\begin{tabular}{|c|c|c|c|c|c|}
\hline Rank & Very low & Low & Moderate & High & Very High \\
\hline Variable & 1 & 2 & 3 & 4 & 5 \\
\hline Relief $(\mathrm{m})$ & $>30$ & $20.1-30.0$ & $10.1-20.0$ & $5.1-10.0$ & $0-5.0$ \\
\hline Rock Type & $\begin{array}{c}\text { Plutonic, Volcanic, } \\
\text { High - medium grade } \\
\text { metamorphics }\end{array}$ & $\begin{array}{c}\text { Low grade met. } \\
\text { Sandstone and } \\
\text { conglomerates. }\end{array}$ & $\begin{array}{c}\text { Most sedimentary } \\
\text { rocks }\end{array}$ & $\begin{array}{c}\text { Coarse and poorly } \\
\text { consolidated sediments }\end{array}$ & $\begin{array}{c}\text { Fine unconsolidated } \\
\text { sediments, volcanic ash. }\end{array}$ \\
\hline Landform & $\begin{array}{c}\text { Rocky, Cliffed coasts, } \\
\text { Fiords, Fiards. }\end{array}$ & $\begin{array}{c}\text { Medium Cliffs, } \\
\text { Indented coasts. }\end{array}$ & $\begin{array}{c}\text { Low cliffs, glacial } \\
\text { drift, salt marsh, coral } \\
\text { reefs, mangrove. }\end{array}$ & $\begin{array}{c}\text { Beaches (pebbles), } \\
\text { estuary, lagoon, } \\
\text { alluvial plains. }\end{array}$ & $\begin{array}{c}\text { Barrier beaches (sand), } \\
\text { mudflats, deltas }\end{array}$ \\
\hline $\begin{array}{c}\text { Vertical movements } \\
\text { (mm/year) }\end{array}$ & $<-1.0$ & $-1.0-0.99$ & $1.0-2.0$ & $2.1-4.0$ & $>4.0$ \\
\hline $\begin{array}{c}\text { Shoreline displacemnets } \\
(\mathrm{m} / \mathrm{yr})\end{array}$ & $>2.0$ Accretion & $1.0-2.0$ & $-1.0-1.0$ Stable & $-1.1--2.0$ & $<-2.0$ Erosion \\
\hline Tidal range $(\mathrm{m})$ & $<1.0$ Microtidal & $1.0-1.9$ & $2.0-4.0$ Mesotidal & $4.1-6.0$ & $>6.1$ Macrotidal \\
\hline Wave height max $(\mathrm{m})$ & $0.0-2.9$ & $3.0-4.9$ & $5.0-5.9$ & $6.0-6.9$ & $>=7.0$ \\
\hline
\end{tabular}

The third step deals with the integration of the factors into a single index. The most common formula for the calculation of CVI is the square root of the mean product of the variables (factors) taken into consideration $C V I=\sqrt{\frac{a \cdot b \cdot c \cdot d \cdot e \cdot f \cdot g}{7}}$ 
Where: $a=$ relief, $b=$ rock type, $c=$ geomorphology, $d=$ relative sea-level rise rate, $e=$ shoreline erosion/accretion rate, $f=$ mean tide range and $g=$ significant wave height.

The fourth step is the classification of CVI values in a vulnerability scale and the GIS mapping of the coastal vulnerability of various segments of the considered shoreline.

\section{Data ranking}

In order to use the considered parameters in the calculation of the CVI their classification in different classes of vulnerability in accordance with Gornitz et al, 1990 is necessary.

Parameter a - Reliefis taken from the topographical map of scale 1:10000 from year 1985 (The Institute of Military Geography). This parameter is very low vulnerability for the hilly part and very high vulnerability for the lowlands of maximum elevation of $5 \mathrm{~m}$.

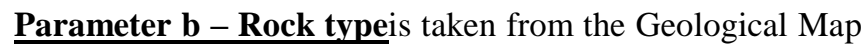
(1:25000) and field surveys. Sedimentary rocks (clays and weakly cemented sandstones) of Pliocene Age and Quaternary soils are encountered in the study area. The sedimentary rocks are classified as moderate vulnerability while the soils are classified as very high vulnerability. The sedimentary rocks cover the hilly part of the area under study.

Parameter c - Landform or geomorphology is interpreted based on Digital Elevation Model ASTER of $30 \mathrm{~m}$ resolution. Low cliffs and sandy beaches are encountered in the study area that correspond respectively to moderate and very high vulnerability.

Parameter d - Sea level rise (vertical movement)is taken from the map of "Trend in Absolute Sea Level across Europe based on satellite measurements, 1992 - 2014, offered by European Environment Agency (EEA) [2]. The sea level rise in the Albanian part of Adriatic Sea is 3-4 $\mathrm{mm} /$ year corresponding to very high vulnerability.

Parameter e - shoreline displacement The coastal changes assessment was conducted using historical data related to the position of the shoreline in different periods. Three shoreline positions (years 1975, 1990 and 2017) corresponding to too time intervalswereexamined. The length of the shoreline that was analysed is about $57 \mathrm{~km}$. The calculation of erosion rates was accomplished using the Digital Shoreline Analysis System (DSAS), created by Thieler and Danforth (1994) [3], [4].
The position of the shoreline was determined using free Landsat Satellites Images offered by Earth Explorer [5] for the years 1975, 1990. The 2017 satellite image was obtained from Sentinel 2 through the Copernicus Program. Sentinel is an Earth observation mission developed by ESA (European Space Agency) and representsa multi-spectral data with 13 bands in the visible near infrared, and short wave infrared part of the spectrum. Spatial resolution is 10 $\mathrm{m}, 20 \mathrm{~m}$ and $60 \mathrm{~m}[6],[7],[8]$.

After obtaining the satellite images they were processed using ArcGIS 10.3. The work consists on the calculation of parameter NDVI (normalized difference vegetation index) with the formula: NDVI=(NIR-RED)/NIR +RED, than each image is classified as unsupervised to form image with complete separation between land and water classes.

The final calculated raster image was converted into polygons. All polygons were converted into polylines and only the line representing the land-water boundary was selected. This procedure was repeated for all datasets. The obtained shoreline for the years 1975, 1990 and 2017 in the vector format was used as the input to the Digital Shoreline Analysis System (DSAS).

DSAS computesthe ratesof shoreline position changes from multiple historic shoreline by using GIS tools. Transects were cast perpendicular to the baseline at a $50 \mathrm{~m}$ interval all along the shore using DSAS. The crossover of these transects with shoreline along the baseline is then used to calculate the rateofshoreline changes. End Point Rate (EPR)method of shoreline change rate estimation was used in this study. The end point rate is calculated by dividing the distance of shoreline movement by the time elapsed between the oldest and the most recent shoreline [3]. Vulnerability ratings were assigned based on the EPR values.

In general, this parameter varies within a high range of values from $-24.3 \mathrm{~m}$ /year (erosion) to $20.2 \mathrm{~m} /$ year (accretion) for the time period of 1975 1990, while for the period 1990 2017, the range of values is between -46.7 $\mathrm{m} /$ year (erosion) to $17.9 \mathrm{~m} /$ year (accretion). In the lowlands of the coast, consisting of sandy beaches, the rates are larger than $2 \mathrm{~m} /$ year corresponding to very high vulnerability class. In various segments, accretion is observed due to the construction of protective works. In the hilly part, the range of values fluctuates significantly. The erosion rates, for the two periods considered, are given in the following Figure:

Public spaces cannot be seen as isolated places but as a public space network, where the most public spaces such as street and squares, provide access to other types of public spaces such parks, markets, shopping malls, cafés or even public buildings such libraries galleries, religious or administrative ones, and even to private spaces and are supplied with people from public spaces such stations, or private spaces such as houses, forming a circular interaction system responsible for the public life of the city and what is more important for social cohesiveness. For that our focus should be in less wall/boundaries approach and more membrane/borders one. 

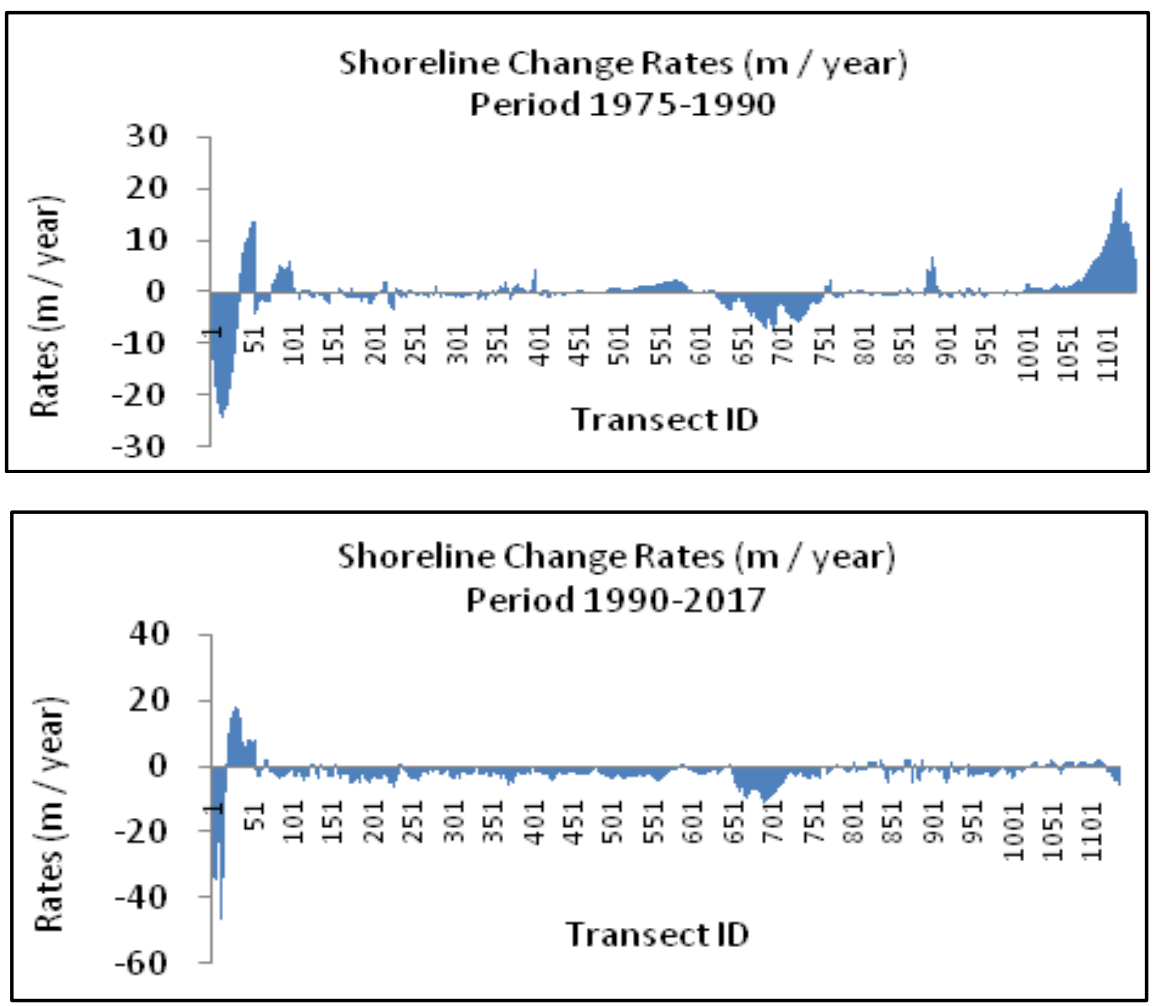

Figure 2: Shoreline change rates

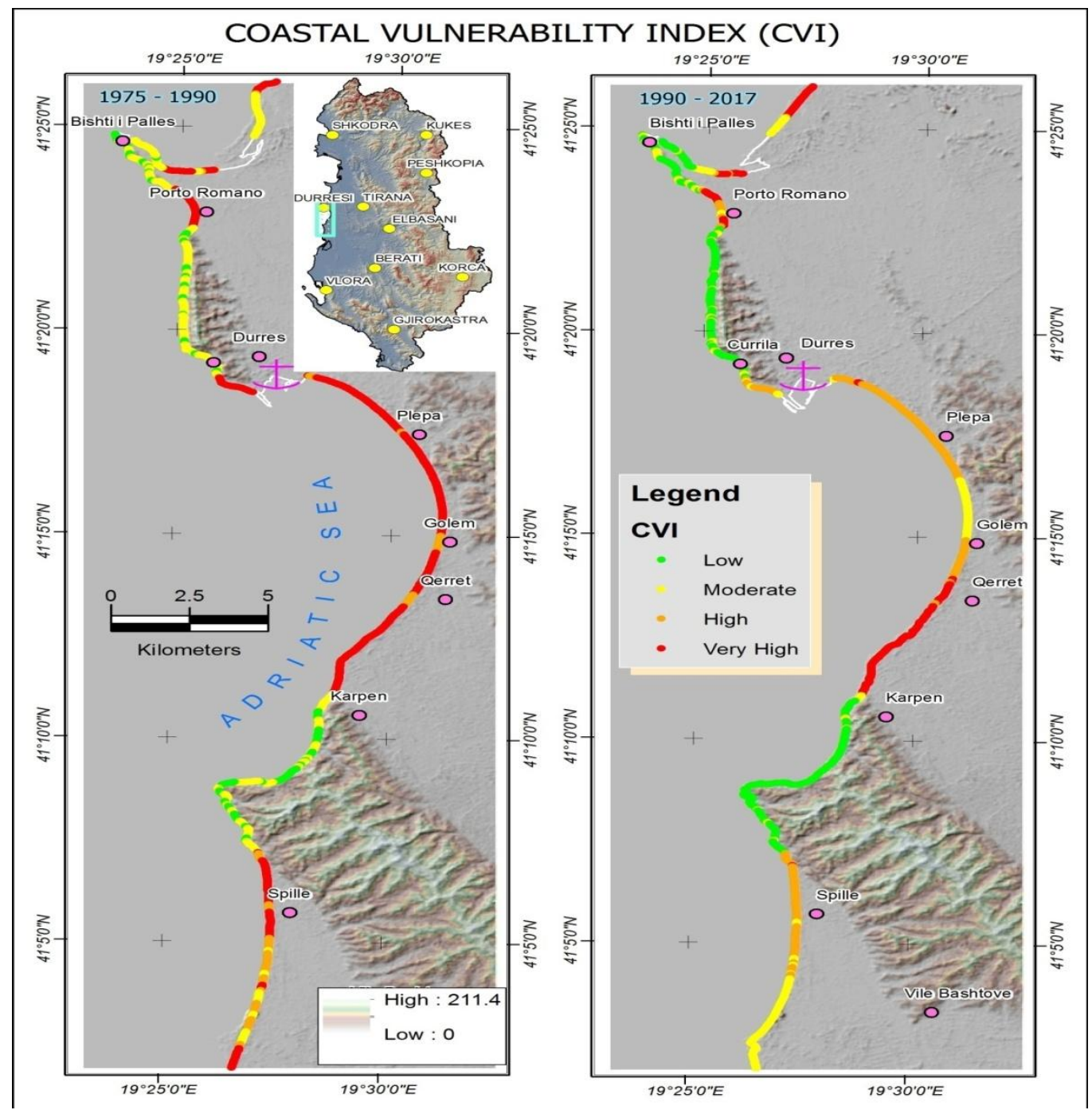

Figure 3: CVI coastal vulnerability index for the 1975-1990 (Left) and 1990-2017 (Right) 
Parameters f and $\mathrm{g}$ - The hydrological parameters are obtained from the publication of the Science Academy of Albania [1]. These parameters are classified as Very low vulnerability. The tidal range in the Albanian part of Adriatic Sea is about $0.4 \mathrm{~m}$ while significant wave height is lower than $0.5 \mathrm{~m}$.

\section{Results and Discussion}

The values of CVI obtained from the analysis vary from 4 to 21 , for both periods considered. This range was divided into 4classes: low (4-8), moderate (9-13), high (14-16), and very high (16-21).The percentiles used to determine the limits of values in ranking the vulnerability classes are the following: percentile $1=25 \%$, percentile $2=50 \%$, percentile $3=75 \%$, percentile $4=90 \%$.

In both periods taken in consideration it can be observed that for the lowlands the values correspond to high and very high vulnerability class, this is especially being the case for the lowland in Durres Bay.If the vulnerability of the shoreline is compared between two periods taken in consideration, it can be observed that the vulnerability for certain sectors decreases and this is related to the construction of protective works.

In the lowlands, in the northern part of the Shkumbini River delta, a decrease of vulnerability is observed related to the fact that the migration of the river mouth northwards at a distance of about $5 \mathrm{~km}$ in the mid 1980's.

At the hilly sections, the variations are minimal and tend towards the decrease of the CVI value.The GIS mapping of CVI values gives a parameter in relation to the vulnerability of the shoreline which can be used by the institutions responsible for the administration and planning of the territory, orienting the interventions with protective works and the application of the developmental projects in specific areas.

It must be noted that Albania is one of the few countries for which such a map is not compiled for the entirety of the shoreline, following the immediate the necessity for undertaking a study for the entire shoreline of Albania.

\section{References}

[1] Akademia e shkencavete RPS teShqiperise. (1984) Hidrologjia e Shqiperise.

[2] https://www.eea.europa.eu/data-andmaps/indicators/sea-level-rise-4/assessment-2

[3] E. R. Thieler, E. A. Himmelstoss, J. L. Zichichi, and T. L. Miller (2005) "Digital Shoreline Analysis System (DSAS) version 3.0:an ArcGIS extension for calculating shoreline change," USGeological Survey Open-File Report 2005-1304, 2005.

[4] https://woodshole.er.usgs.gov/projectpages/DSAS/version3/

[5] https://earthexplorer.usgs.gov/

[6] https://sentinel.esa.int/web/sentinel/missions/sentinel-2

[7] https://sentinel.esa.int/web/sentinel/userguides/sentinel-2-msi

[8] https://scihub.copernicus.eu/
[9] Gornitz, V., 1990. Vulnerability of the East Coast, U.S.A. to future sea level rise. Journal of Coastal Research, Special Issue No. 9, p. 201-237. 